\title{
Spexin in Metabolic Syndrome-An Overview
}

Tejaswi Gowdu, Dayanand. CD*

Department of Biochemistry, Sri Devaraj Urs Medical College, SDUAHER, Kolar, Karnataka, India

DOI: $10.36347 /$ sasjm.2021.v07i01.005

| Received: 14.01.2021 | Accepted: 24.01.2021 | Published: 28.01.2021

*Corresponding author: Dr. Dayanand. CD

Abstract

Review Article

Spexin (SPX) is a neuropeptide hormone or adipokine secreted from adipose tissue an endocrine organ and that undergoes post-translational modification of $\alpha$-amidation at C-terminal. Neuronal signal stimulation causes release of SPX into synapse where it binds to G-protein coupled receptors which involve in signal transduction. SPX co-evolved with galanin/Kisspeptin family. It is 14 amino acids containing mature peptide and its sequence was highly conserved in vertebrates and non-vertebrates. SPX C12ORF39 gene and mRNA were widely expressed in central nervous system and peripheral nervous system in goldfish, rodents and humans. Cognate receptors of SPX are GalR2/GalR3 involves in regulating food intake, body weight and energy homeostasis through neuroendocrine functions. Current research suggested that SPX also regulate glucose and lipid metabolism. Adipose tissue secretes adipocytokines which plays pivotal role in regulating lipid and glucose metabolism, storage, food intake, energy expenditure. Down regulation of SPX gene and its concentration in serum was associated with obesity which further leads to components of metabolic syndrome such as T2DM, HTN and CVDs. Metabolic syndrome (MetS) is affecting the general population and has been higher risk of developing cardiovascular morbidity and mortality. Severity of this syndrome leads to decreased quality of life in humans. Clear explanation of intracellular signalling pathways and its receptors would help to develop novel therapeutic interventions and drug design for disorders like obesity and T2DM. In this review we focus to provide an updates about SPX and its physiological role in metabolic syndrome.

Keywords: Biomarker, Metabolic syndrome, Spexin.

Copyright $(\mathcal{C} 2021$ The Author(s): This is an open-access article distributed under the terms of the Creative Commons Attribution 4.0 International License (CC BY-NC 4.0) which permits unrestricted use, distribution, and reproduction in any medium for non-commercial use provided the original author and source are credited.

\section{INTRODUCTION}

Adipose tissue is with specialised loose connective tissue composed of adipocytes and endocrine in nature [1]. Two types of adipose tissue are Brown and white adipose tissues, former one present in adult humans, while the latter one is predominantly found in neonates. White adipose tissue mainly as Visceral fat plays a vital role in energy storage which secretes variety of adipokines such as Leptin, adiponectin, resistin, retinol binding protein-4, Vaspin, Tumour necrosis factor- $\alpha$ (TNF- $\alpha$ ), Interleukin-6, Visfatin, Apelin, Insulin Growth Factor-1, hormones like estrogen and glucocorticoides [2, 3]. Amongst, adipocytokines, adiponectin, leptin plays a crucial role in inflammation process, metabolism of glucose and lipids [4]. Spexin is a recently identified neuropeptide also termed as Adipokine involved in energy homeostasis [5, 6].

However, human Markov Model-a bioinformatics approach/search tool had been adopted to identify the features of new peptide hormones sequence. Since, spexin is also a short peptide hormone signalling through membrane receptors to exert a crucial role in physiological and pathological conditions. Biochemical analysis revealed that spexin co-localised with insulin in secretory vesicles of pancreatic $\beta$-cell line and suggested that it could be processed and secreted at cellular level by exocytosis [7].

Spexin (SPX) has pleotropic functions, it is highly expressed in pancreas and almost all the tissues [8]. SPX acts through cognate receptors with several physiological roles in regulation of glucose and lipid metabolism, GI tract motility, energy balance, nociception/mood disorders, weight loss, acts as satiety inducing peptide, in reproduction, renal and Cardiovascular diseases (CVD) [9, 10]. Despite, SPX precursors was predominantly expressed in sub mucosal layer of stomach in rats and mouse oesophagus and causes stimulation of muscle contractions [7]. 
Tejaswi Gowdu \& Dayanand. CD, SAS J Med, Jan, 2021; 7(1): 15-25

Pathologically, spexin as aadipokine may be associated with metabolic syndrome components such as obesity, Insulin resistance; dyslipidaemia which may subsequently increase the risk of Diabetes and CVD complications [11]. Due to increased prevalence of metabolic syndrome, it is important to explore on further aspects of molecular mechanisms with respect to its regulation on therapeutic research and drug design of SPX [12]. Recent studies indicated on SPX physiological role in lipid, glucose, and energy metabolism with respect to energy expenditure and balance. Whereas, in metabolic diseases like obesity, diabetes and cardiovascular diseases, the seldom information available on mechanism of action of spexin [13].

\section{Structure of Spexin}

Spexin belongs to family of galanin/Kisspeptin encoded by C12ORF39 gene located on chromosome $12 \mathrm{p} 12.1$. This neuropeptide hormone released as prepropeptide, Spexin has 116 amino acid residues by zymogen/proenzyme process followed by 14 amino acids mature peptide fringed by dibasic cleavage sites with molar mass 13,302 (Figure 1) [14, 15].

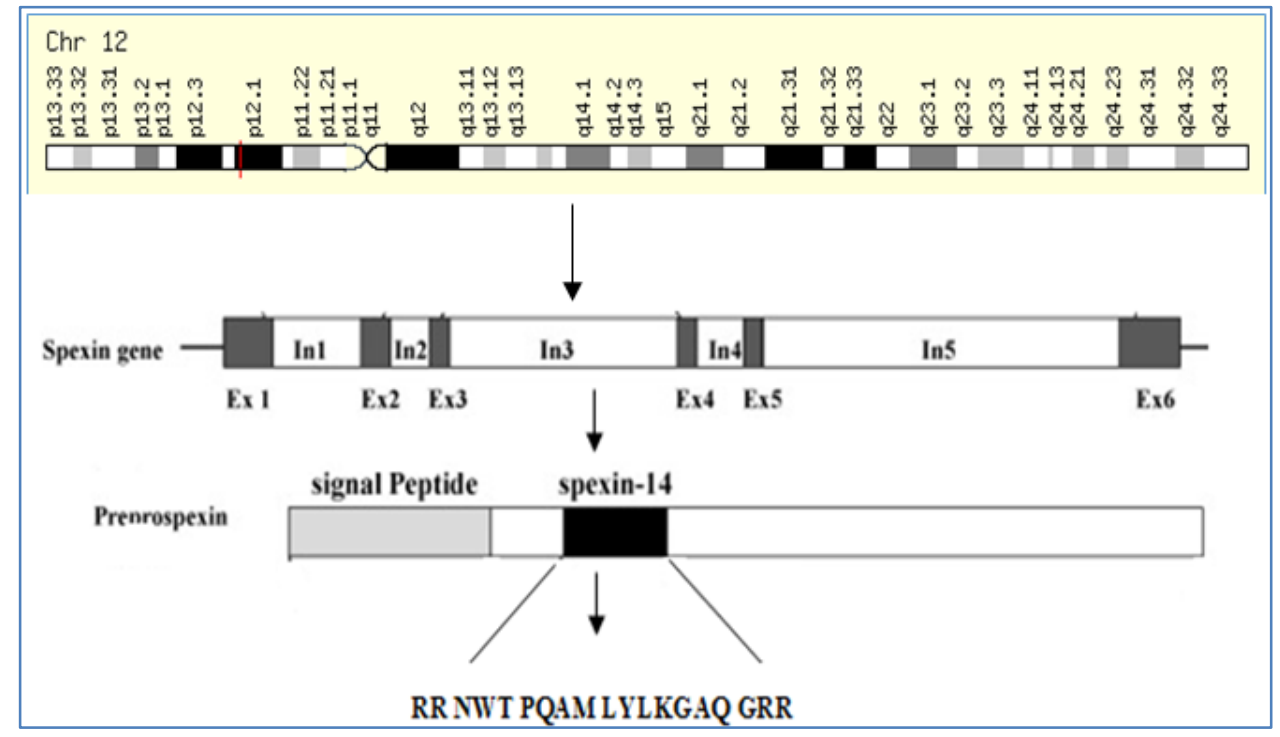

Fig-1: Structure of Spexin. In humans, alignment of spexin gene contains six exons and five introns convert's preprospexin 116 amino acids to prospexin 14 amino acids mature peptide which was highly conserved and flanked by dibasic cleavage sites [6]

In humans, SPX gene and its transcribing unit's codes at $5^{1}$ end that has promoter region followed by comprising 6 exons and 5 introns [16]. In contrast, SPX gene in goldfish and zebra fish at $5^{1}$ end that has promoter region which contains 5 exons and 4 introns [17]. Hence, SPX mature peptide sequence comprises of $3^{\text {rd }}$ and $4^{\text {th }}$ while signal peptide holds $1^{\text {st }}$ and $2^{\text {nd }}$ exons [7]. An experimental study in goldfish showed that SPX releases three mRNA transcripts with different length $(847,805$ and 574 bp) by alternative introns splicing, nevertheless mature peptide sequence of SPX carries mRNA transcript of only $574 \mathrm{bp}$, whereas other two do not carry mRNA transcript due to presence of stop codon in the sequence of introns which was observed in only goldfish and hence the variation might be showed either from quantitative real time PCR (or) in-situ hybridization by primer sequence for analysis Wong et al. discovered about the 3D structure of SPX in goldfish for the first time [9].

\section{D structure of human spexin}

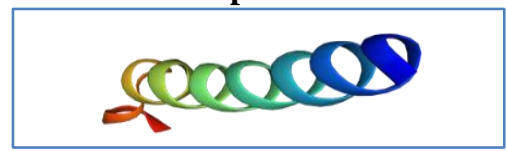

Fig-2: Structure of spexin. Source (www.uniport.org)
Three dimensional structure of the spexin has been provided in Figure 2. NMR spectroscopy revealed that Asparagine, Tryptophan, Threonine and Proline are the first four peptide sequence of fish SPX, forms an arbitrary structure at N-terminal and which further forms $\alpha$-helix structure with remaining amino acids (514) in C-terminal and this spectroscopy indicates that molecular surface of fish SPX is highly hydrophobic except for charged residue named as lys [11]. Since the mature peptide sequence across the species is highly conserved, suggested that peptide play a role in binding/activation of SPX receptors which further involves in regulating a variety of physiological \& pathological functions. Among variety of species including mammals, SPX peptide sequence (NWTPQAMLYLKGAQ) was identical except for panda, cat and dog with substitution from Ala [6] to Ser [6]. Based on knowledge based modelling, in mammals 3D structure amino acid sequence of spexin from $\mathrm{Thr}$ [13] to Ala [13] substitution forms a $\alpha$-helix as conflict to substitution from $\mathrm{Ala}^{13}$ to $\mathrm{Thr}^{13}$ in ray-finned fishes (Figure 3) [18]. 


\begin{tabular}{|c|c|}
\hline \multicolumn{2}{|c|}{$\begin{array}{ll}\text { NWT PQAM LYLKGAQ } & \text { tetrapods } \\
\text { NWT PQAM LYLKGTQ } & \text { bony fish }\end{array}$} \\
\hline $\begin{array}{l}\text { Human } \\
\text { Mouse } \\
\text { Rat } \\
\text { Panda } \\
\text { Dog } \\
\text { Cat } \\
\text { Chicken } \\
\text { Lizard } \\
\text { Xenopus } \\
\text { Coelacanth } \\
\text { Zebrafish } \\
\text { Fugu } \\
\text { Goldfish } \\
\text { Ya-fish } \\
\text { Grouper }\end{array}$ & $\begin{array}{l}\text { RRNWT PQAM LYLKGAQGRR } \\
\text { KRNWT PQAM LYLKGAQGRR } \\
\text { KRNWT PQAM LYLKGAQGRR } \\
\text { RRNWT PQSM LYLKGAQGRR } \\
\text { RRNWT PQSM LYLKGAQGRR } \\
\text { RRNWT PQSM LYLKGAQGRR } \\
\text { RRNWT PQAM LYLKGAQGRR } \\
\text { RRNWT PQAM LYLKGAQGRR } \\
\text { RRNWT PQAM LYLKGAQGRR } \\
\text { RRNWT PQAM LYLKGAQGRR } \\
\text { RRNWT PQAM LYLKGTQGRR } \\
\text { RRNWT PQAM LYLKGTQGRR } \\
\text { RRNWT PQAM LYLKGTQGRR } \\
\text { RRNWT PQAM LYLKGTQGRR } \\
\text { RRNWT PQAM LYLKGTQGRR }\end{array}$ \\
\hline Consensus & NWT PQ ${ }_{\mathrm{A}}^{\mathrm{S}} \mathrm{M}$ LYLKG $\underset{T}{\mathrm{~A}} \mathbf{Q}$ \\
\hline
\end{tabular}

Fig-3: SPX1 mature peptide sequence in humans and non-vertebrates. In humans, amino acid sequence was identical, except in panda, dog and cat the Ala [6] is substituted to Ser [6] and in remaining non-vertebrates the substitution from Ala [13] to Thr [13] was seen [6]

Data mining and comparative synteny analysis revealed that SPX was classified into SPX1and SPX2. SPX1 was found only in mammals and SPX2 was found in fishes \& birds. Despite, the cleavage site in rat is replaced from Arginine to histidine (GKR) instead of Gly-Arg-Arg (GRR) which was found in mammals, and suggesting that mature peptide of SPX1 and SPX2 plays an important physiological role in vertebrates $[9$, 10].

\section{Receptors of spexin (GalR2 and GalR3)}

According to Molecular evolution, the amino acid positions in SPX1 is similar with Gal at corresponding positions 2,3,9,10 and 12 which indicates that positions of Gal at Try2, Thr3, Tyr9 are the key determinants for interaction between SPX and
GalR and as well as its binding \& activation. The mature peptide sequence from SPX2 differs from SPX1 at position $3^{\text {rd }}$ (ThrVsGly), $6^{\text {th }}$ (AlaVsSer), $13^{\text {th }}$ (ThrVsArg or Ala) and $14^{\text {th }}$ (GlnVs His or Tyr) Kisspeptin \& SPX do not have similar sequence [20].

In mammals, cognate receptors for SPX1 are GalR2 and GalR3 which are again sub classified into GalR1, GalR2 and GalR3. In other vertebrates like zebrafish GalR1 again classified into (GalR1a and GalR1b) and GalR2 into (GalR2a and GalR2b). Although in teleost genome, GalR3 was absent [6]. Hence, a ligand-receptor study proved that SPX is a natural ligand and SPX1 in humans where as SPX2 in non-vertebrate's species activates Galanin receptor 2/3 but not GalR1 (1a and 1b) (Figure 4).

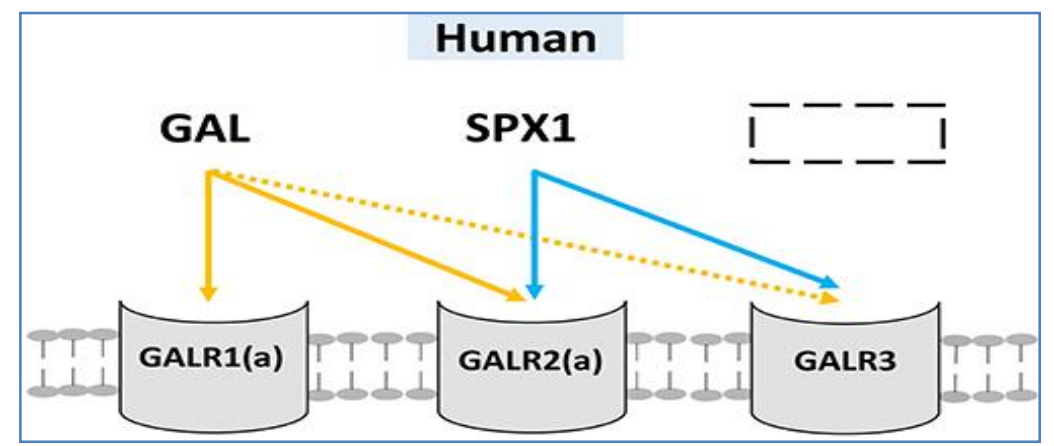

Fig-4: Receptors of SPX in humans. SPX1 is predominantly expressed in humans. SPX1 will binds to receptors GalR2 (a) and GalR3 with high affinity but not to GalR1 where as SPX2 is absent in humans and Gal binds to GalR1a and GalR2 (a) [9]

In Zebra fish and Xenopus, both SPX1 and SPX2 show higher affinity towards GalR2b compared to Gal. [10]. Nevertheless, in teleost GalR2a receptors shows shorter terminus and highly conserved than with that of human GalR2a receptors [21]. This GalR2a/2b receptors reserve some crucial amino acids such as His 253, Tyr 271, Phe 264 and His 252 in human GalR2a receptors for recognition of ligand binding with 
Tejaswi Gowdu \& Dayanand. CD, SAS J Med, Jan, 2021; 7(1): 15-25

exception of GalR2b where tyrosine residue was substituted in the position of His 252 [21]. In both mammalian and non-mammalian vertebrates SPX was restricted across the species and presented in a wide range of tissues and organs. Therefore, SPX1 \& SPX2 are widely distributed in the brain of gold fish, Zebra fish and rodents [9].

\section{Biosynthesis and secretion of Spexin}

All the processed peptides undergo posttranslational modifications. Therefore, mature peptide causes $\alpha$-amidation at $\mathrm{C}$-terminal which may shows its effects on receptors binding [6]. These mature peptides processed and secreted by secretory pathway into extracellular space, where it binds to its receptors and shows its effects on cellular functions [7]. Signal peptide of Spexin is converted to pro-hormone with the help of an enzymes pro-hormone convertases and signal peptidases. The enzyme peptide-glycine $\alpha$ amidatingmonoxygenase cleaves at GRR/GKR target site, which further undergoes $\alpha$-amidation by posttranslational modification at $\mathrm{C}$-terminal that shows effect on its stability/receptor binding (Figure 5) [6, 19].

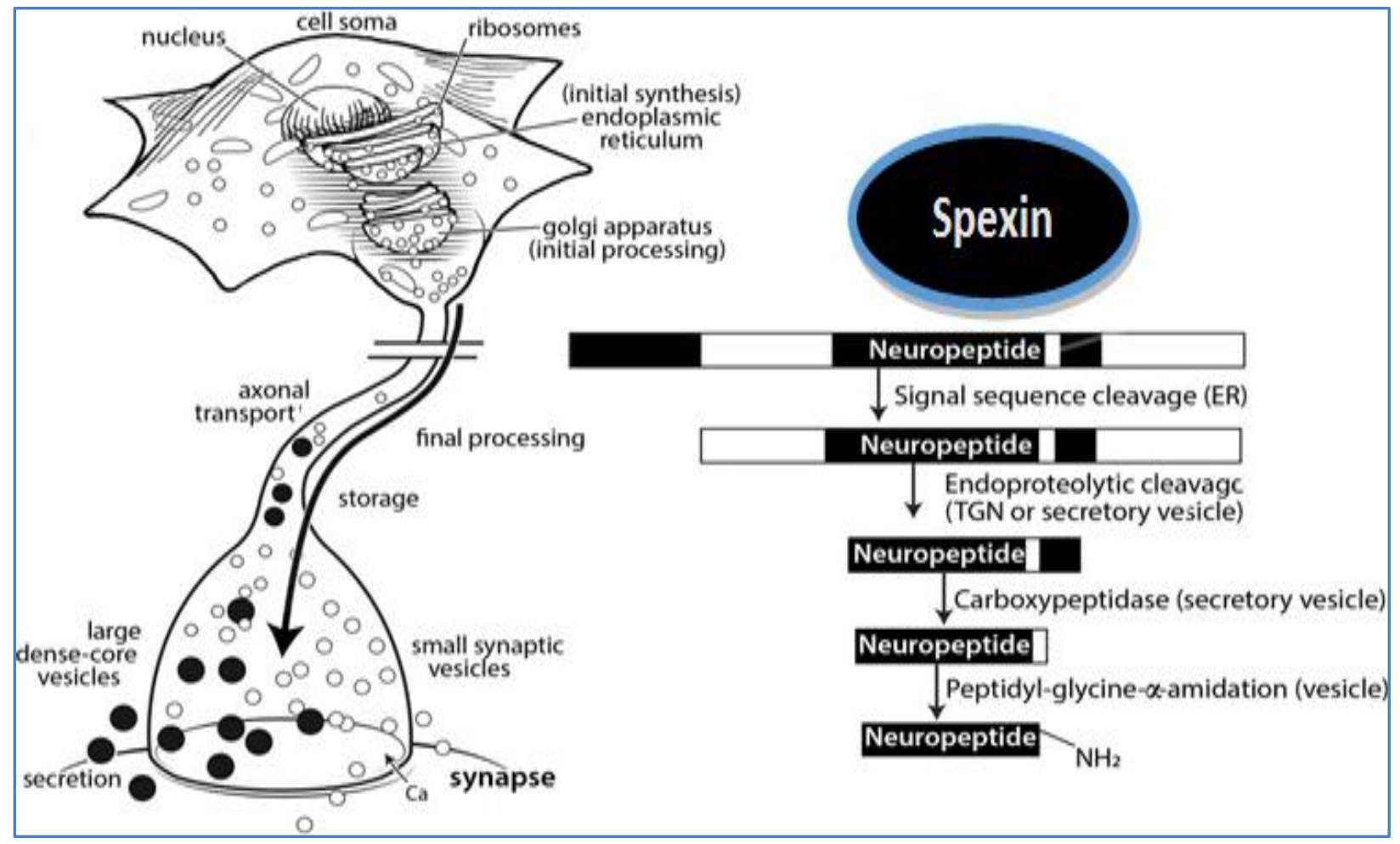

Fig-5: Mature peptide synthesis and secretion. Mature peptides processed and secreted by secretory pathway into extracellular space, where it binds to its receptors and shows its effects on cellular functions by post-translational modifications through its receptors [46].

In general, signal transduction actions occur through G-protein coupled receptors (GPCRs) by binding of different types of signal molecules. Most of the peptide hormones are ligands. GPCRs having 7 transmembrane receptors family spanning membrane [22]. Cognate receptors of SPX are GalR2/3. The biological functions of $\mathrm{Gal}$ are well documented for differential regulation of PI3K/Akt- dependent cascades, MAPK, cAMP/PKA and Calcium through coupling of GalR2 with Gq/11 and GalR3 with Gi receptors [23, 24]. Though the receptors are similar for SPX and Galanin (i.e) GalR2 and GalR3, the signal transduction pathways which were involved in biological role of SPX are not illustrated.

\section{Quantification of Spexin}

The method employed for estimations of SPX levels in serum, plasma, and tissue fluids is ELISA method (immune-based technique-enzyme linked immunosorbent assay. Results based on this method in several research studies give varied information in MetS.

\section{Principle of ELISA}

The principle of ELISA for the estimation of SPX is an enzyme-linked antibody sandwich method. Procedure for ELISA method is the microtitre plate is pre-coated with an antibody specific to SPX. Biotinconjugated antibody specific and standards or samples which are specific to SPX are added to wells of microtitre plate. Streptavidin conjugated to horseradishperoxidase is added and incubated, and then addition of tetramethylbenzidine substrate solution to wells containing only SPX, Streptavidin conjugated antibody and biotin-conjugated antibody which will give colour. The enzyme-substrate reaction is end up by adding stop 
Tejaswi Gowdu \& Dayanand. CD, SAS J Med, Jan, 2021; 7(1): 15-25

reagent and change of the colour is measured at a wavelength of $450 \mathrm{~nm}$. The SPX concentration is determined by comparing the absorbance with standard curve. Representing the units for measuring SPX is in nanogram/pictogram per millilitre [5].

\section{Physiological roles of Spexin}

\section{Role of Spexin in appetite and weight regulation}

Experiment done in goldfish suggested that SPX expression was stimulated by food intake which regulates appetite in brain, hypothalamus, telencephalon and optic tectum. In central expression after feeding in goldfish there will be an increased insulin signal which was caused by increased blood glucose from pancreas as well as secretion of insulin from liver by paracrine/autocrine effect to stimulate SPX secretion and expression at hepatic level. ICV injection of SPX causes inhibitory effect of food intake by SPX is mediated by upregulation like anoregenic,
Corticotropin releasing hormone $(\mathrm{CRH})$, Proopiomelanocorticon (POMC) and Melanocytecorticon hormone $(\mathrm{MCH})$ and downregulation of oregenic, Neuropeptide (NPY), apelin and Agouti related receptor protein (AgRP) [17]. Hence, SPX decreases food intake/feeding behaviour. After feeding absence of SPX increases Agouti related receptor protein gene whereas after treatment with SPX it decreases Agouti related receptor protein gene suggested that SPX regulates food intake by Agouti related receptor protein gene (Figure 6) [25].

\section{Spexin in Body weight}

Key regulator for body weight control is long chain fatty acid uptake and its storage. SPX shows its effects by inhibiting Long chain fatty acid uptake, increased locomotor activity and decreased respiratory exchange ratio in adipocyte of mice [26]. Hence, suggested that SPX shows inhibitory effect on body weight with obesity.

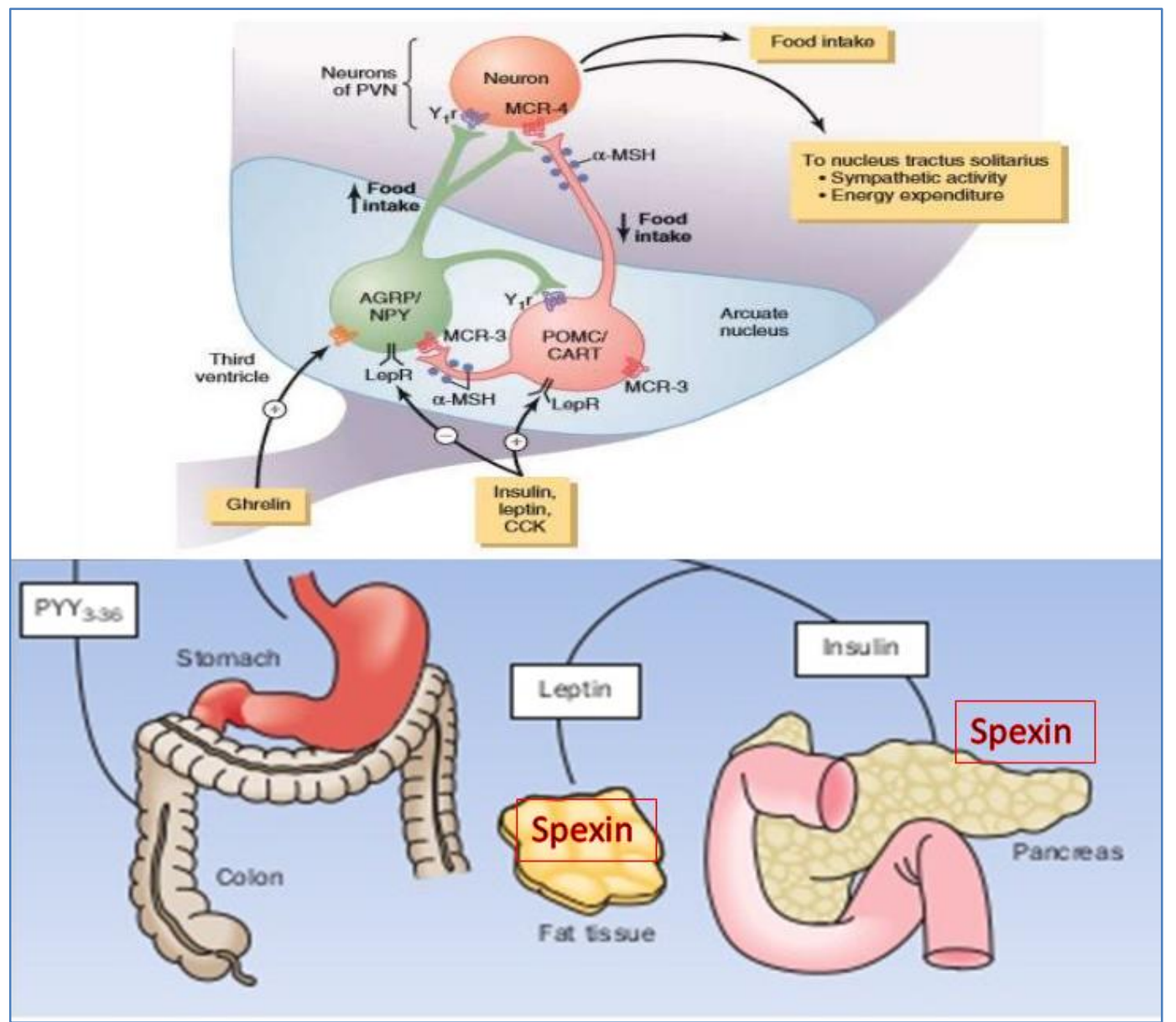

Fig-6: Regulation of spexin in weight and food intake. SPX causes inhibitory effect of food intake by upregulation like anoregenic, Corticotropin releasing hormone (CRH), Pro opiomelanocorticon(POMC)\&Melanocytecorticon hormone (MCH) and downregulation of oregenic, Neuropeptide (NPY), apelin and Agouti related receptor protein (AgRP) (47)

\section{Spexin in Lipid metabolism}

In humans, adipocytes, SPX causes decreased in transcriptional factors such as Peroxisome proliferatoractivator receptor gamma, c/ebp $\alpha, \mathrm{c} / \mathrm{ebp} \beta$ and c/ebp $\gamma$ leads to inhibition of lipogenesis and glucose uptake and stimulation of lipolysis by phosphorylation of Hepatic lipase. Hence, indicates that SPX involves in regulation of lipid metabolism [12]. Recently, in mice with hepatic steotosis/non-alcoholic fatty liver disease causes decreased hepatic lipid, aspartate 
Tejaswi Gowdu \& Dayanand. CD, SAS J Med, Jan, 2021; 7(1): 15-25

aminotransferase, alanine transaminsase by intraperitoneal injection of SPX [27].

\section{Spexin in Gastrointestinal tract}

Activation of L-type voltage dependent $\mathrm{Ca}^{2+}$ channels through GalR2 receptors of SPX leads to stimulation of bowel motility and decreases constipation. Therefore, SPX play an important role in Gastro intestinal tract functions [18].

\section{Spexin in Glucose metabolism}

SPX maintains glucose tolerance and decreases insulin resistance in obese mouse with T2DM [15] suggesting that SPX plays a role in glucose metabolism [27]. Thus, SPX improve cell viability, proliferation of pancreatic cells, up regulation of protein levels of proliferating cell nuclear antigen [12].

\section{Spexin in bile acid synthesis}

SPX intraperitoneal injection causes decreased mRNA levels of the enzymes such as cholesterol $7 \alpha-$ hydroxylase mRNA and sterol $12 \alpha$-hydroxlase leads to decreased chenodeoxycholic acid, and cholic acid by bile acid co-aminoacid $\mathrm{N}$ - aceytltransferase which further decreases conjugated bile acids like Cholic acid, Glycocholic acid, Tauro $\beta$-muricholate, Taurotransporter gene, taurourosodeoxycholate. Hence, leads to decreased bile acids (Figure 7) [29].

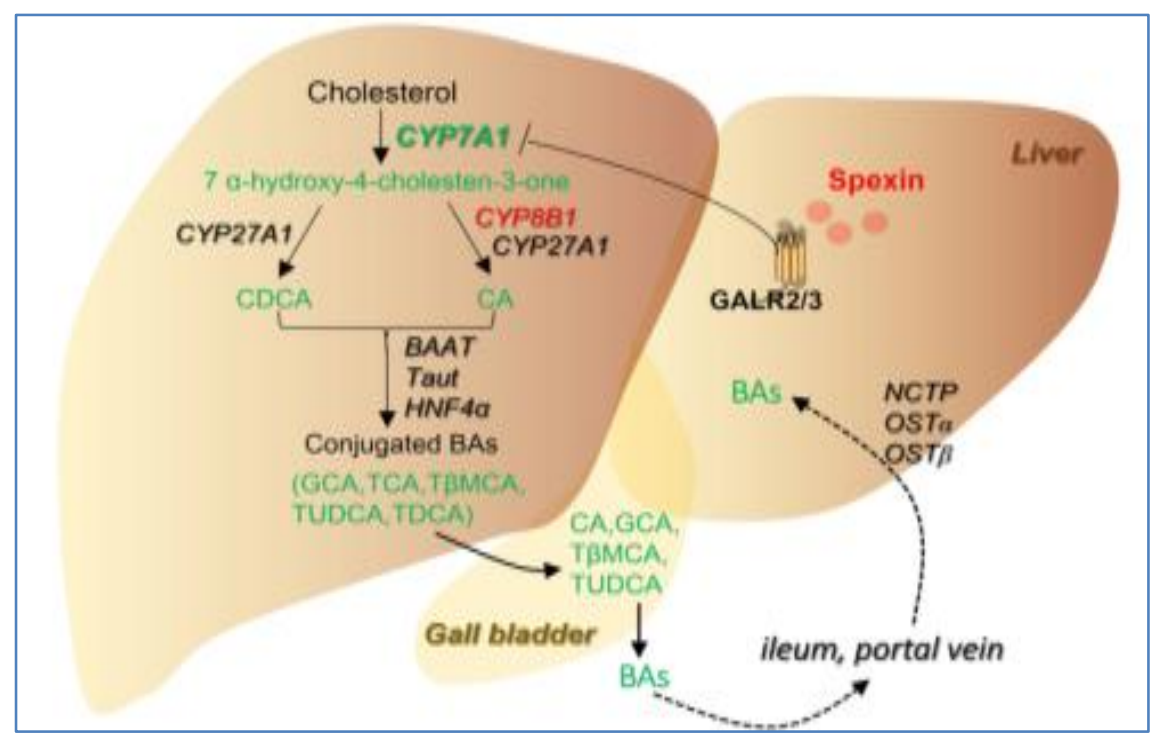

Fig-7: SPX role on synthesis of bile acids. Decreased mRNA expression of cholesterol 7- $\alpha$ - hydroxylase 1 and chenodeoxycholic acid (CDCA), and cholic acid (CA), stimulates bile acid co-aminoacid N- aceytltransferase (BAAT) decreases Cholic acid,

Glycocholic acid, Tauro $\beta$-muricholate, Tauro-transporter gene, taurourosodeoxycholate. Finally decreased total bileacids [29]

\section{Spexin in Reproductive system}

Studies had reported that treatment with SPX in hypothalamus of fish flat causes upregulation of gonadotropin inhibitory hormone \& gonadotropinreleasing hormone and downregulation of growth hormone, FSH (Follicle stimulating hormone) suggesting that SPX involved in regulation of reproductive system by inhibition of Leutinizing hormone (LH) [30].

\section{Spexin role in Pain, Depression and anxiety}

In mouse, intra cerebro ventricular administration of SPX produced anti nociceptive effect $[31,32]$. Administration of SPX centrally reduces inflammatory pain with inhibition of dynorplin/opioid pathway by producing antinoceptive effects [33]. Intra cerebro ventricular injection of SPX based GALR2specific agonists produced anxiolytic effect in mice [34].

\section{Spexin in Blood pressure}

Intra-cerebro-ventricular SPX injection causes decreased arterial pressure, sodium reabsorption, cardiac output and normal urine output which indicates that SPX involves in CVDs and renal functions activation [6] Therefore, overall SPX biological functions through its receptors suggested that it also involves in learning, memory, mood disorders, but still the signal transduction pathways through SPX based Galanin receptors was unknown [10].

\section{Genetic Study in Humans}

Hala Abdulhade Salih et al. found that Circulating serum's Spexin level was significantly decreased in obese children due to $70 \%$ of Transition and transvertion mutations were observed in the spexin gene sequences in DNA of obesity group than in the control and also observed gene mutation in the 5 untranslated region 5UTR and 3 untranslated region 3UTR compared to controls. Hence, mutation in spexin gene may affected very low serum spexin levels and its 
expression in the obese children compared to control's serum [48].

\section{Role of Spexin in metabolic syndrome}

SPX plays a major role in glucose and lipid homeostasis. Decreased or lack of SPX levels may leads to obesity and insulin resistance. Since it is a satiety-inducing factor it regulates food intake. But in obesity its gene is downregulated and increases uptake of Long chain fatty acid in adipose tissue. Visceral fat deposits contribute to insulin resistance, as it leads to release of free fatty acids enters to liver [37]. From liver, these free fatty acids result in more production of glucose, triglycerides, apoB100 and low density lipoprotein. Hence, secretion of increased very low density lipoprotein apoB100 leads to more fat accumulation [38]. Where as in muscle, on acute exposure free fatty acids inhibit insulin-mediated glucose uptake which leads to reduced insulin sensitivity [39]. So, triglycerides are increased due to more deposition of Long chain fatty acid uptake in adipose tissue. Studies have reported that the pathogenesis of hepatic steatosis is due to increased Long chain fatty acid uptake, its disposition and increased triglycerides leads to progression of obesity. In healthy persons, the adipocyte normal physiological role is for meal-related diurnal variations, Long chain fatty acid uptake with their facilitated transporter, its degradation by $\beta$-oxidation and its elimination through lipolysis. In contrast, obese subjects are associated with increased release of Long chain fatty acid, activation of $\beta$-oxidation and its enzymes which causes lipolysis (i.e adenylate cyclise signalling cascade) leading to impaired Long chain fatty acid metabolism [40]. Overview of SPX differential physiological function was provided in Figure 8.

\section{Spexin correlation studies with other metabolic biomarkers}

Studies have shown that SPX levels are negatively correlated with blood glucose, HbA1c, triglycerides, low density lipoprotein and total cholesterol in diabetes patients and demonstrate that SPX play a role in glucose and lipid metabolism [29]. Recent study found that SPX is negatively correlated with insulin and glucagon in obese female and revealed that SPX involved in glucose regulation and insulin resistance [41].

However, SPX levels independently predict the risk of high body mass index, and fasting glucose and concluded that circulating SPX levels decrease with age [42]. In 2018, Kolodziejski et al studied the correlation between levels of SPX or kisspeptin in obese and non-obese patients with body mass index, Homeostatic Model Assessment of Insulin resistance, serum levels of insulin, glucagon, leptin, adiponectin, orexin-A, obestatin, ghrelin and found that SPX and kisspeptin levels are decreased in obese patient compared to non-obese subjects and concluded that the
SPX and kisspeptin show negative correlation with obesity, Insulin resistance [41]. But Guo et al. said that Galanin has opposite effects when compared to SPX which leads to increased expression and Glucose transporter type-4 membrane translocation, body weight and leads to obesity [43]. In 2018, Daghri AL et al. included 124 metabolic syndrome patients, among them 41 males and 83 females in a cross sectional study and found that decreased SPX levels are moderately associated with metabolic syndrome components and are sex-specific in adults $[44,45]$. Therefore, SPX and leptin may be a potential biomarker for future CVDs. But the pathophysiology of SPX with obesity, Insulin resistance and CVDs through its receptors is unclear [13].

\section{In vitro studies}

Studies have shown that experiment done in brain and hepatocytes of goldfish suggested that glucose-stimulated SPX gene expression increase insulin secretions [6]. Similar author done on immunereactivity Studies of SPX and reported that SPX was co-localised with the insulin in secretory vesicles, which implies SPX is coevolved and co-released with insulin [6]. Some studies demonstrated that in stomach muscle of rat and mouse, SPX causes contractile activity and decreases constipation by explant assay [7]. Previous studies demonstrated that protein signals of SPX are located in secretory vesicles and there it has been processed and revealed at cellular level along with insulin by exocytosis in culture medium of pancreatic $\beta$ TC3 cells [17]. Earlier studies has reported that Escitalopram which was an antidepressant and injected in hypothalamus of rats caused decreased SPX gene expression whereas in hippocampus of rats showed increased SPX gene expression suggested that SPX play a role in regulating the depression [35].

\section{Spexin role in energy and mitochondrial homeostasis in cardiomyocytes (in vitro studies)}

Yang Liu et al. conducted a study on the roles of SPX in regulating hypoxia-induced alterations in energy metabolism and mitochondrial function. Spexin levels was treated with and without exposure to hypoxia in primary neonatal rat ventricular myocytes (NRVMs) and found that exposure to hypoxia in vitro reduces SPX level in NRVMs and with spexin before hypoxia exposure causes regulation of fatty acid metabolism (FAT/CD36, CPT1, ACADM, and PPAR-a and PGC1-a) improves uptake of glucose and significantly prevented the down regulation of mitochondrial electron transport chain complex and restrained UCP2 level and reactive oxygen species (ROS) production, thus enhancing ATP level in cardiomyocytes. Hence suggested that SPX protects energy and mitochondrial homeostasis of cardiomyocytes during hypoxia and useful in the treatment of cardiovascular diseases [49]. 


\section{Controversial studies}

Earlier studies reported that glucose stimulated SPX gene expression increase insulin secretions in brain and hepatocytes of goldfish [6]. Contradictory to above study demonstrated that inhibition of insulin secretions by SPX not only observed in cultured and isolated islets but also in obese rats [36].

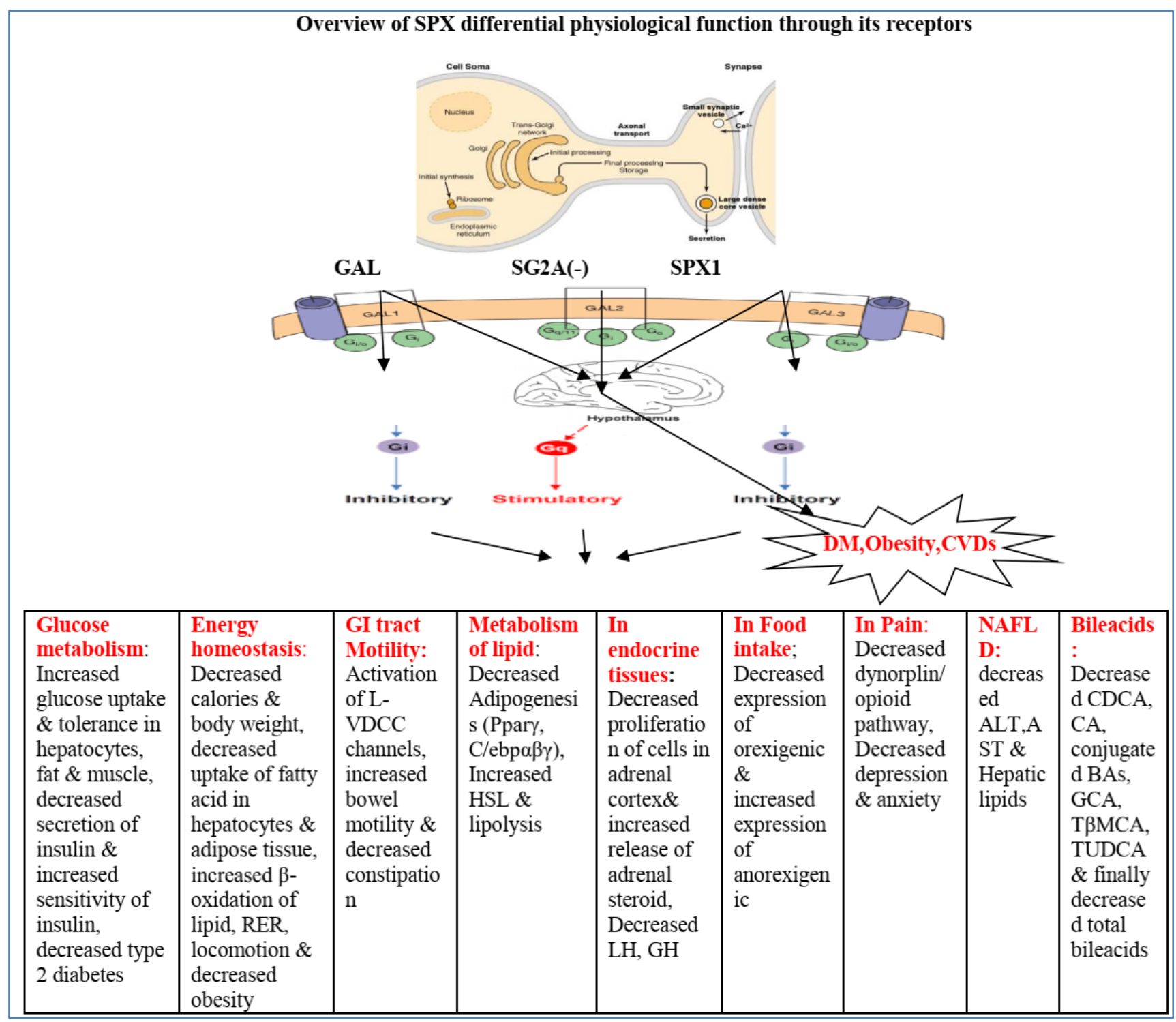

Fig-8: Spexin physiological and pathological functions. SPX is a peptide hormone contains 116a.as preprohormone undergoes proteolytic cleavage into 14a, as mature peptide which is highly conserved and undergoes post-tranlational modifications at Cterminal and stores in secretory vesicles. When there is a signal through neurons the mature peptide secreted by classic secretory pathway into ectracellular space and binds to GalR2/3 receptors by GPCRs receptors and undergoes stimulation of intracellular signalling pathways with spexin based galanin receptors.

\section{Therapeutic interventions}

Studies have reported that SPX intra-cerebroventricular and peripheral injection in gold fish causes decreased in Agouti related receptor protein gene which leads to decreased food intake/ feeding behaviour [17]. Another study had shown that in obese rats, SPX reduces food intake by giving SPX injection subcutaneously. Similar author reported that in adipocytes of mice, SPX treatment inhibit effects of Long chain fatty acid uptake while intra-peritoneal injection in mice causes increased locomotor activity and decreased respiratory exchange ratio [24]. SPX treatment in mice liver with non-alcoholic fatty liver disease shows beneficial effect by reduced Long chain fatty acid uptake [28]. In humans SPX intra-peritoneal injections increases intestinal transit rate and promoter colonic bead explusion [18].

\section{Human studies on increased Spexin levels}

Khadir A. et al. reported that regular physical excercise can also increase the levels of Spexin to manage obesity and healthy lifestyle [50]. Al-Daghri, N.M. et al. also suggested that the effect of 6-month self-monitored life style modification programme increases spexin levels in adult females with prediabetes [51]. Another longitudinal study done by 
Tejaswi Gowdu \& Dayanand. CD, SAS J Med, Jan, 2021; 7(1): 15-25

the author Kumar s et al., reported that patients with Roux-en-Y bypass \& severe obesity in young adults showed post-surgery increased spexin levels.

\section{Future prospective}

The signal transduction pathways through Spexin-based galanin receptors are still need to be elucidated. Epidemiological studies should be done in different ethnic groups on SPX levels which may give a clear idea of SPX cut offs in patients with Mets and healthy individuals. Hence literature was sparse. To enhance good quality of life in human's future studies should be explore on diet, lifestyle modifications, SPX therapies which helps to manage obesity and T2DM. Several clinical trials, longitudinal and randomised controlled trails are necessary to explore about SPX functions through its receptors. Experimental studies should be done on SPX gene.

\section{CONCLUSION}

Spexin is a neuropeptide which was highly conserved in vertebrates. The cognate receptors for SPX are Glar2/3. SPX was expressed in almost all tissues. Through its receptors it plays a role in differential regulation on food intake, energy balance and energy expenditure, smooth muscle contractions in GI tract, glucose and lipid metabolism (Long chain fatty acid uptake), nociception/CVDs/renal functions \& in reproduction as well. Decreased SPX levels in blood were a risk assessment of the disease. Therapeutic drug design and recombinant SPX preparations will be useful for treatment of obesity \& metabolic disorders in future to ensure the quality of human life.

\section{REFERENCES}

1. Pawlina W. Histology A Text and Atlas with correlated cell and molecular biology In:Adipose tissue. Histology, editor. 7th edition. Philadelphia: Wolters Kluwer Health. 2015:254.

2. Curat CA, Miranville A, Sengenès $C$, Diehl $M$, Tonus C, Busse R, Bouloumié A. From blood monocytes to adipose tissue-resident macrophages: induction of diapedesis by human mature adipocytes. Diabetes. 2004 May 1;53(5):1285-92.

3. William T. Shearer, MD, PhD, Lanny J. Rosenwasser, MD, and Bruce S. Bochner, MD. Adipose tissue, adipokines, and inflammation. J Allergy ClinImmunol. 2005;115(5):911-919.

4. Cao H. Adipocytokines in obesity and metabolic disease. J Endocrinol. 2014;220(2):T47-T59.

5. Behrooz M, Vaghef-Mehrabany E, Ostadrahimi A. Different Spexin level in Obese vs Normal Weight Children and Its Relationship with Obesity Related Risk Factors. Nutrition, Metabolism and Cardiovascular Diseases. 2019.

6. Ma A, Bai J, He M, Wong AO. Spexin as a neuroendocrine signal with emerging functions. Gen Comp Endocrinol.2018;265:90-6.

7. Mirabeau O, Perlas E, Severini C, Audero E, Gascuel O, Possenti R, Birney E, Rosenthal N,
Gross C. Identification of novel peptide hormones in the human proteome by hidden Markov model screening. Genome research. 2007 Mar 1;17(3):320-7.

8. Porzionato A, Rucinski M, Macchi V, Stecco C, Malendowicz LK, De Caro R. Spexin expression in normal rat tissues. Journal of Histochemistry \& Cytochemistry. 2010;58(9):825-37.

9. Lee MYM, Soga T, Parhar I. Evolution of structural and functional diversity of Spexin in mammalian and non-mammalian vertebrate species. Frontiers in Endocrinology. 2019;10:379.

10. Kim DK, Yun S, Son GH, Hwang JI, Park CR, Kim JI, Kim K, Vaudry H, Seong JY. Coevolution of the spexin/galanin/kisspeptin family: Spexin activates galanin receptor type II and III. Endocrinology. 2014 May 1;155(5):1864-73.

11. Ghadge AA, Khaire AA. Leptin as a predictive marker for metabolic syndrome. Cytokine. 2019;121:154735.

12. Lv SY, Zhou YC, Zhang XM, Chen WD, Wang YD. Emerging roles of NPQ/spexin in physiology and pathology. Frontiers in pharmacology. 2019 May 7;10:457.

13. Kumar S, Hossain M, Javed A, Kullo IJ, Balagopal PB. Relationship of circulating spexin with markers of cardiovascular disease: a pilot study in adolescents with obesity. Pediatric obesity. 2018;13(6):374-80

14. Sonmez K, Zaveri NT, Kerman IA, Burke S, Neal CR, Xie X, Watson SJ, Toll L. Evolutionary sequence modeling for discovery of peptide hormones. PLoS Comput Biol. 2009 Jan 9;5(1):e1000258.

15. Gu L, Ma Y, Gu M, Zhang Y, Yan S, Li N, Wang Y, Ding X, Yin J, Fan N, Peng Y. Spexin peptide is expressed in human endocrine and epithelial tissues and reduced after glucose load in type 2 diabetes. Peptides. 2015 Sep 1;71:232-9.

16. Li S, Liu Q, Xiao L, Chen H, Li G, Zhang Y, Lin H. Molecular cloning and functional characterization of spexin in orange-spotted grouper (Epinephelus coioides). Comparative Biochemistry and Physiology Part B: Biochemistry and Molecular Biology. 2016 Jun 1;196:85-91.

17. Wong MK, Sze KH, Chen T, Cho CK, Law HC, Chu IK, Wong AO. Goldfish spexin: solution structure and novel function as a satiety factor in feeding control. American Journal of PhysiologyEndocrinology and Metabolism. 2013 Aug 1;305(3):E348-66.

18. Lin CY, Zhang M, Huang T, Yang LL, Fu HB, Zhao L, Zhong LL, Mu HX, Shi XK, Leung CF, Fan BM. Spexin enhances bowel movement through activating L-type voltage-dependent calcium channel via galanin receptor 2 in mice. Scientific reports. 2015 Jul 10;5(1):1-2.

19. Merkler DJ. C-terminal amidated peptides: production by the in vitro enzymatic amidation of glycine-extended peptides and the importance of 
the amide to bioactivity. Enzyme and microbial technology. 1994 Jun 1;16(6):450-6.

20. Carpenter KA, Schmidt R, Yue SY, Hodzic L, Pou C, Payza K. The Glycine1 Residue in Cyclic Lactam Analogues of Galanin (1- 16)-NH2 Is Important for Stabilizing an N-Terminal Helix. Biochemistry. 1999;38(46):15295-304.

21. Martins RS, Pinto PI, Guerreiro PM, Zanuy S, Carrillo M, Canário AV. Novel galanin receptors in teleost fish: identification, expression and regulation by sex steroids. General and comparative endocrinology. 2014;205:109-20.

22. Vasudeven DM. Mechanisms of Action of Hormones and Signalling Molecules. New delhi;Jayapee Brothers Medical Publishers (P) Ltd: 2013: 650.

23. Lang R, Gundlach AL, Holmes FE, Hobson SA, Wynick D, Hökfelt T, Kofler B. Physiology, signaling, and pharmacology of galanin peptides and receptors: three decades of emerging diversity. Pharmacological reviews. 2015 Jan 1;67(1):11875.

24. Šípková J, Kramáriková I, Hynie S, Klenerová V. The galanin and galanin receptor subtypes, its regulatory role in the biological and pathological functions. Physiological research. 2017;66(5):72940 .

25. Zheng B, Li S, Liu Y, Li Y, Chen H, Tang H, Liu $\mathrm{X}$, Lin $\mathrm{H}$, Zhang $\mathrm{Y}$, Cheng $\mathrm{CH}$. Spexin suppress food intake in zebrafish: evidence from gene knockout study. Scientific reports. 2017 Nov 7;7(1):1-9.

26. Walewski JL, Ge F, Lobdell IV H, Levin N, Schwartz GJ, Vasselli JR, Pomp A, Dakin G, Berk $\mathrm{PD}$. Spexin is a novel human peptide that reduces adipocyte uptake of long chain fatty acids and causes weight loss in rodents with diet-induced obesity. Obesity. 2014 Jul;22(7):1643-52.

27. Ge JF, Walewski JL, Anglade D, Berk PD. Regulation of Hepatocellular Fatty Acid Uptake in Mouse Models of Fatty Liver Disease with and without Functional Leptin Signaling: Roles of NfKB and SREBP-1C and the Effects of Spexin. Seminars in liver disease. 2016 Sep;36(4):360-72. PubMed PMID: 27997977. Epub 2016/12/21. eng.

28. Ma A, He M, Bai J, Wong MK, Ko WK, Wong AO. Dual Role of Insulin in Spexin Regulation: Functional Link between Food Intake and Spexin Expression in a Fish Model. Endocrinology. 2017 Mar 1;158(3):560-77. PubMed PMID: 28359089. Epub 2017/03/31. Eng

29. Lin C-y, Zhao L, Huang T, Lu L, Khan M, Liu J. Spexin acts as novel regulator for bile acid synthesis. Frontiers in physiology. 2018;9:378.

30. Liu Y, Li S, Qi X, Zhou W, Liu X, Lin H. A novel neuropeptide in suppressing luteinizing hormone release in goldfish, Carassius auratus. Molecular and cellular endocrinology. 2013 Jul 15;374(12):65-72. PubMed PMID: 23623870. Epub 2013/04/30. eng.
31. Toll L, Khroyan TV, Sonmez K, Ozawa A, Lindberg I, McLaughlin JP, et al. Peptides derived from the prohormone proNPQ/spexin are potent central modulators of cardiovascular and renal function and nociception. FASEB journal: official publication of the Federation of American Societies for Experimental Biology. 2012 Feb;26(2):947-54.

32. Moazen P, Taherianfard M, Ahmadi Soleimani M, Norozpor M. Synergistic effect of spexin and progesterone on pain sensitivity attenuation in ovariectomized rats. Clinical and experimental pharmacology \& physiology. 2018 Apr;45(4):34954.

33. Lv SY, Cui B, Yang Y, Du H, Zhang X, Zhou Y. Spexin/NPQ Induces FBJ Osteosarcoma Oncogene (Fos) and Produces Antinociceptive Effect against Inflammatory Pain in the Mouse Model. The American journal of pathology. 2019 Apr;189(4):886-99.

34. Reyes-Alcaraz A, Lee Y-N, Son GH, Kim NH, Kim D-K, Yun S. Development of Spexin-based Human Galanin Receptor Type II-Specific Agonists with Increased Stability in Serum and Anxiolytic Effect in Mice. Scientific Reports. 2016 2016/02/24;6(1):21453

35. Palasz A, Suszka-Switek A, Filipczyk L, Bogus K, Rojczyk E, Worthington J. Escitalopram affects spexin expression in the rat hypothalamus, hippocampus and striatum. Pharmacological reports: PR. 2016 Dec;68(6):1326-31.

36. Sassek M, Kolodziejski PA, Strowski MZ, Nogowski L, Nowak KW, Mackowiak P. Spexin Modulates Functions of Rat Endocrine Pancreatic Cells. Pancreas. 2018 Aug;47(7):904-9.

37. Lewis GF, Steiner G. Acute effects of insulin in the control of VLDL production in humans. Implication for the insulin resistant state. Diabetes Care. 1996;19(4):390-3.

38. Miles JM, Jensen MD. Counterpoint: visceral adiposity is not causally related to insulin resistance. Diabetes Care. 2005;28(9):2326-8.

39. Boden G, Lebed B, Schatz M, Homko C, and Lemieux S. Effects of Acute Changes of Plasma Free Fatty Acids on Intramyocellular Fat Content and Insulin Resistance in Healthy Subjects. DIABETES. 2001; 50:1612-17.

40. Aganovi I, Dusek T. Pathophysiology of metabolic syndrome. 2007;1-7.

41. Kołodziejski PA, Oszmałek PE, Korek E, Sassek M, Szczepankiewicz D, Kaczmarek P. Serum levels of spexin and kisspeptin negatively correlate with obesity and insulin resistance women. Physiol Res. 2018;67(1):45-56.

42. Lin C-y, Zhao L, Huang T, Lu L, Khan M, Liu J. Circulating Spexin Levels Negatively Correlate with Age, BMI, Fasting Glucose, and Triglycerides in Healthy Adult Women. Journal of the Endocrine Society. 2018;2(5): 409-419. 
43. Guo L, Shi M, Zhang L, Li G, Zhang L, Shao H. Galanin antagonist increases insulin resistance by reducing glucose transporter 4 effect in adipocytes of rats. General and comparative endocrinology. 2011 Aug 1;173(1):159-63.

44. Al-Daghri NM, Alenad A, Hazmi H, Amer OE, Hussain SD, Alokail MS. Spexin Levels Are Associated with Metabolic Syndrome Components. Dis Markers. 2018;4:1-5

45. Kumar S, Hossain J, Nader N, Aguirre R, Sriram $\mathrm{S}$, and Balagopal P. Decreased Circulating Levels of Spexin in Obese Children. J ClinEndocrinolMetab. 2016;101(7): 2931-2936.

46. Russo AF. Overview of neuropeptides: awakening the senses? Headache. 2017 May; 57(Suppl 2): 3746.

47. Guyton and Hall. Dietary balances; regulation of feeding;obesity and starvation;vitamins and minerals.12th ed.2016.
48. Salih HA, Al-Shamaa SD. Correlation between spexin gene mutation and iraqi children obesity. Journal of Critical Reviews. 2020;7(3):514-23.

49. Liu Y, Sun L, Zheng L, Su M, Liu H, Wei Y, Li D, Wang Y, Dai C, Gong Y, Zhao C. Spexin protects cardiomyocytes from hypoxia-induced metabolic and mitochondrial dysfunction. NaunynSchmiedeberg's archives of pharmacology. 2020 Jan;393(1):25-33.

50. Khadir A, Kavalakatt S, Madhu, D. Spexin as an indicator of beneficial effects of exercise in human obesity and diabetes. Sci Rep. 2020; 10, 10635 (2020). https://doi.org/10.1038/s41598-020-67624$\mathrm{Z}$

51. Al-Daghri NM, Alenad A, Hazmi H, Amer OE, Hussain SD, Alokail MS. Favourable changes in fastisng glucose in a 6-month self- monitored lifestyle modification programme inversely affects spexin levels in females with prediabetes. Nature. 2019;4:1-5. 